\title{
Anatomical Evidence for Direct Projections from the Entorhinal Area to the Entire Cortical Mantle in the Rat
}

\author{
L. W. Swanson and C. Köhler* \\ The Howard Hughes Medical Institute, The Salk Institute for Biological Studies, La Jolla, California 92037, and \\ *ASTRA Research Laboratories, Department of Pharmacology, ASTRA, Södertälje, Sweden
}

\begin{abstract}
The entorhinal area is the most highly differentiated cortical field of the hippocampal formation from an anatomical point of view, and is best known as the origin of the perforant pathway, a massive association projection to the molecular layer of the dentate gyrus and Ammon's horn. This pathway is important as the first link in the so-called "trisynaptic circuit," which is thought to form the basic unit of information processing in the hippocampal formation and has been implicated in the elaboration of short-term memory and the more permanent storage of selected events in other parts of the cortical mantle. We have reexamined the efferent projections of the lateral entorhinal area with a sensitive new method that utilizes the anterograde axonal transport of a lectin, Phaseolus vulgaris leukoagglutinin (PHA$\mathrm{L}$ ), that is not internalized by fibers of passage, and displays labeled axons with the clarity of Golgi impregnations. The results of 5 experiments with injections confined entirely to the lateral entorhinal area suggest that this area sends fibers to innervate the entire cortical mantle, as well as to a longitudinal zone extending the length of the striatum (nucleus accumbens and medial caudoputamen) and the basolateral complex of the amygdala. In an additional series of experiments, injections of the fluorescent retrograde tracer fast blue that were centered in medial prefrontal, somatosensory, auditory, and motor areas of the cortex invariably labeled many neurons in layer IV of the lateral entorhinal area, as well as in other layers, depending on the site of injection. Finally, the results of double retrograde tracer experiments indicated that the 2 densest projections from the lateral entorhinal area - to the medial prefrontal region and to the dentate gyrus and Ammon's horn-arise from essentially separate populations of neurons. These findings serve to clarify the neural mechanisms underlying the role of the hippocampal formation in learning and memory, as well as in locomotor activity associated with goal-oriented behavior.
\end{abstract}

The entorhinal area, which corresponds to Brodmann's area 28, gives rise to a massive association pathway that ends preferentially in the molecular layer of the dentate gyrus and Ammon's horn (Cajal, 1911). Because this fiber system courses transversely through the subiculum, it is called the "perforant path," and it forms the initial link in a series of excitatory pathways known as the "trisynaptic circuit," which is thought to provide the basic unit for information processing in the hippocampal formation (Andersen et al., 1971; Winson and Abzug, 1978). The functional significance of this highly organized cortical circuitry has never been clear, although it has attracted a great deal of interest

Received Feb. 6, 1986; revised Mar. 27, 1986; accepted Apr. 1, 1986.

We would like to thank Dr. R. W. Lind for preparing the retrograde doublelabeling material. This work was supported in part by NIH Grant NS-16686.

Correspondence should be addressed to Dr. L. W. Swanson, The Salk Institute, P.O. Box 85800, San Diego, CA 92138-9216.

Copyright (C) 1986 Society for Neuroscience $0270-6474 / 86 / 103010-14 \$ 02.00 / 0$ recently as a possibly important component of neural mechanisms underlying short-term memory and the more permanent consolidation of particular events in other regions of the cortex (Squire and Zola-Morgan, 1983). This hypothesis was based originally on the observation of scvere memory deficits in patients with bilateral damage to medial parts of the temporal lobe (Scoville and Milner, 1957). Since then it has become clear that the hippocampal formation receives information from each of the sensory modalities, and the suggestion has even been made that it elaborates a "cognitive map" of the animal's cnvironment (O'Keefe and Nadel, 1978). Furthermore, this line of reasoning has been strengthened by the discovery of the long-term potentiation of synaptic efficacy in major links of the intrahippocampal circuitry (for a review, see Swanson et al., 1982), as well as by neuropathological evidence for the early and severe loss of entorhinal neurons (particularly in layers II and IV) in dementia of the Alzheimer type (Hyman et al., 1984) and for the selective loss of neurons in field $\mathrm{CA}_{1}$ of Ammon's horn in a patient with amnesia (Zola-Morgan et al., 1986).

If the hippocampal formation does play an important role in learning and memory, one might deduce that it must establish an intricate series of connections with the rest of the cerebral cortex, although anatomical evidence for such pathways has accumulated only recently. Surprisingly, this evidence indicates that the densest cortical inputs to the entorhinal area arise within other parts of the hippocampal formation itself, including the pre- and parasubiculum (Köhler, 1985; Shipley, 1975), the subiculum (Shipley and Sorensen, 1975), and field CA Cf Am- $_{1}$ mon's horn (Swanson and Cowan, 1977). However, it now seems clear that the entorhinal area also receives direct inputs from the olfactory bulb and piriform (olfactory) cortex (Kosel et al., 1981; Krettek and Price, 1977), as well as from inferior (Van Hoesen and Pandya, 1975a) and superior (Amaral et al., 1983) temporal, orbitofrontal (Van Hoesen et al., 1975), lateral prefrontal (Goldman-Rakic et al., 1984), and perirhinal (Van Hoesen and Pandya, 1975a) cortical association areas. In addition, the presubiculum receives direct inputs from inferior temporal (Van Hoesen et al., 1975), lateral prefrontal (Goldman-Rakic et al., 1984; Irle and Markowitsch, 1982), and inferior parietal (Jones and Powell, 1970; Seltzer and Van Hoesen, 1979) association areas. Therefore, it would appear that the entorhinal and subicular components of the hippocampal formation receive direct inputs from a wide variety of multimodal association areas, at least in the primate where this issue has been examined in particular detail. There is also evidence in the rat that visual (Vogt and Miller, 1983) and auditory (Vogt and Miller, 1983) areas may project directly or indirectly to the preand/or parasubiculum.

The anatomical evidence also indicates that these parts of the hippocampal formation project back to several other cortical fields. Thus, the entorhinal area has been shown to send fibers to olfactory cortical regions in the rat (Haberly and Price, 1978a, 
b; Krayniak et al., 1981; Krettek and Price, 1977; Sorensen and Witter, 1983; Wyss, 1981), and quite recently Sorensen (1985) has reported that it also projects to the entire cingulate gyrus and medial prefrontal cortex, as well as to the perirhinal and insular regions in the guinea pig. In addition, the presubiculum sends fibers to prefrontal, temporal, and cingulate association areas (Goldman-Rakic et al., 1984; Rosene and Van Hoesen, 1977; Swanson and Cowan, 1977), and the subiculum and field $\mathrm{CA}_{1}$ project directly to medial prefrontal areas (Swanson, 1981).

It now seems clear, therefore, that the parahippocampal gyrus establishes bidirectional connections with a number of other multimodal frontal, temporal, and cingulate areas, on the one hand, and the dentate gyrus and Ammon's horn on the other. We have begun to reexamine these projections with the sensitive new anterograde tracer Phaseolus vulgaris leukoagglutinin, PHA-L (Gerfen and Sawchenko, 1984). Small injections have been made in each field of the parahippocampal gyrus of the rat, and, in the present report, we describe the organization of projections from the lateral entorhinal area (area 28a) to other parts of the telencephalon. The results clearly indicate that neurons in the lateral entorhinal area collectively innervate all parts of the cortical mantle, as well as a longitudinal zone in medial parts of the striatum and the basolateral complex of the amygdala. Furthermore, this conclusion has been substantiated by the results of experiments with injections of the retrograde tracer fast blue into a number of different cortical fields, and double retrograde tracer experiments indicate that separate neurons in the lateral entorhinal area send fibers through the perforant path and to the prefrontal cortex.

\section{Materials and Methods}

Six brains with small iontophoretic injections of PHA-L confined to the lateral entorhinal area were used in this study. For comparison, brains with injections in adjacent areas were also examined, although the results will not be described in detail here; these injections included 4 in the medial entorhinal area, 2 in the presubiculum, 3 in the subiculum, and 1 in the perirhinal area. The injections and histology were carried out according to Gerfen and Sawchenko (1984), as described elsewhere (Köhler, 1985). In brief, a 1 in 3 series of $30 \mu$ m-thick frozen sections were cut in the horizontal plane and were reacted for PHA-L immunohistochemistry using a biotin-avidin-HRP detection system. Alternate series were stained with thionin for cytoarchitectonic details, or were osmicated to intensify the immunohistochemical staining. The major advantages of the PHA-L method are that fibers of passage are not labeled and that anterogradely labeled axons are stained with the clarity of Golgi impregnations. In addition, the method is quite sensitive, and the injection site can be defined accurately on the basis of filled cell bodies (Gerfen and Sawchenko, 1984).

Injections of the fluorescent tracer fast blue (Kuypers et al., 1980) were also made into several cortical fields, and the distribution of retrogradely labeled neurons was plotted in the hippocampal formation. For this, approximately $50 \mathrm{nl}$ of a $2 \%$ aqueous solution was injected stereotaxically through a glass micropipette, and after a 5-10 d survival time the brains were processed and analyzed as described elsewhere (Köhler et al., 1984). In addition, double retrograde tracer experiments were carried out to determine whether neurons in the entorhinal area project both to the medial prefrontal region and through the perforant path. Three different combinations of tracers were used. First, $1 \mu \mathrm{l}$ of a $2 \%$ aqueous solution of diamidino yellow (Keizer et al., 1983) was injected stereotaxically through a Hamilton microsyringe into the medial prefrontal region, and 3 crystalline deposits of fast blue were made with a glass micropipette (Simerly and Swanson, 1986) into the dentate gyrus and hippocampus; the animals were perfused $3 \mathrm{~d}$ later. Second, $1 \mu \mathrm{l}$ of fluorescent latex microspheres (Katz et al., 1984) was injected into the medial prefrontal region in the same way, and 3 crystalline deposits of fast blue were made in the dentate gyrus and hippocampus; the animals were perfused $3 \mathrm{~d}$ later. And third, 2 crystalline deposits of fast blue were placed in the medial prefrontal region and, $3 \mathrm{~d}$ later, 3 injections of $2.5 \%$ wheat germ agglutinin (Lechan et al., 1981; Ruda and Coulter, 1982) in potassium phosphate buffer were made iontophoretically from a glass micropipette $(50 \mu \mathrm{m}$ in diameter) into the dentate gyrus and hippocampus; the animals were perfused $2 \mathrm{~d}$ later.

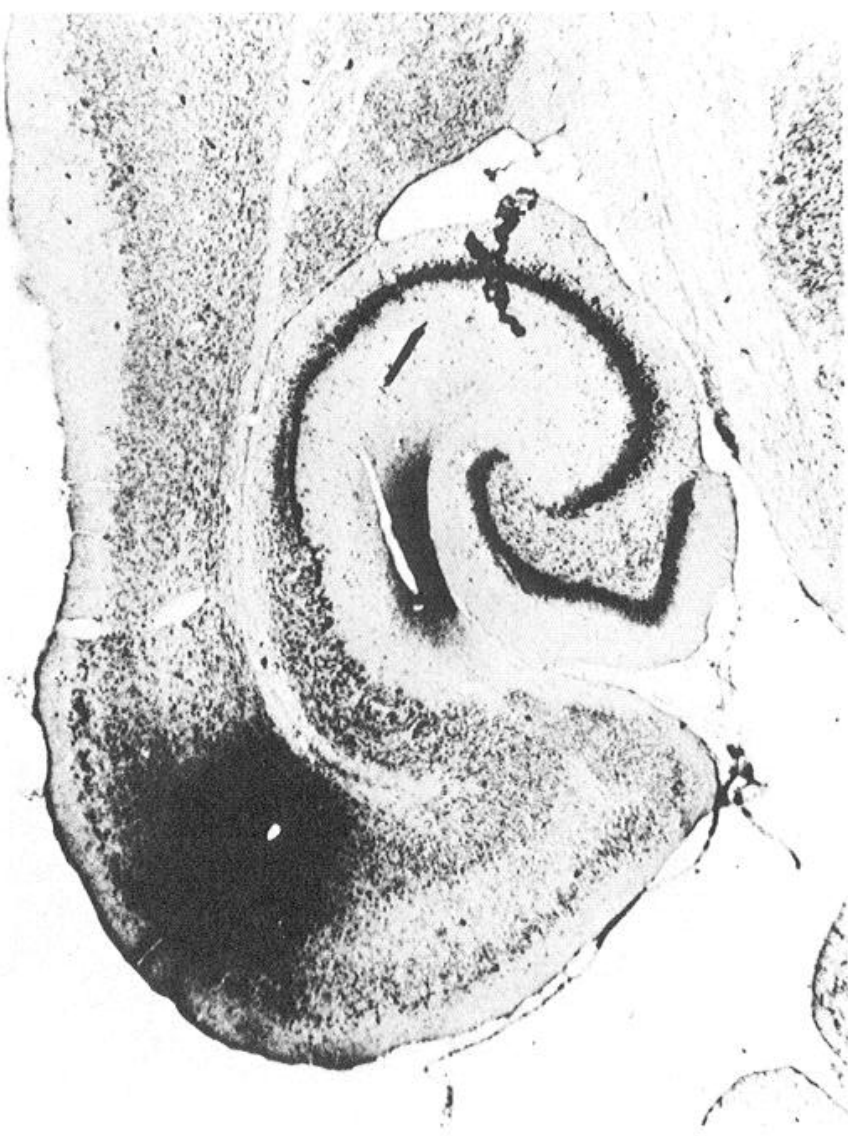

Figure 1. Low-power photomicrograph of the PHA-L injection site in experiment 311 ; note dense deposit of the tracer confined to the lateral entorhinal area, and dense labeling of the perforant path in Ammon's horn and the subiculum. This Nissl-stained horizontal section lies approximately between $B$ and $C$ in Figure 2 . At this magnification $(\times 15)$ and photographic exposure, it is not possible to resolve, within the region of the injection site, individual labeled neurons, a diffuse spread of PHA$\mathrm{L}$, or labeled fibers proceeding from the injection site.

\section{Results}

\section{Anterograde transport experiments}

Six experiments with injections of PHA-L that labeled only cell bodies in the lateral entorhinal area were examined in detail. In all but one case the pattern of anterograde fiber labeling in the telencephalon was qualitatively similar. Therefore, we shall describe the results of 1 of these 5 experiments (311) in detail.

The injection site was centered in the deep layers of the lateral entorhinal area (Figs. 1,2), although a few cells were also heavily labeled in layers II and III. On the basis of cell counts, it was estimated that on the order of 1500 neurons were labeled in this injection site. The injection site in the exceptional case was centered in layer II, and gave rise to much less dense labeling, except in the molecular layer of the dentate gyrus, which was massively labeled (see below).

The pattern of axonal labeling in the forebrain of 311 is illustrated schematically in Figure 2. In all areas the labeled axons were varicose, and at least some displayed clear terminal boutons; only the density, laminar distribution, and orientation of these fibers varied from one region to another. For the sake of completeness, the distribution of intrahippocampal association pathways arising in the lateral entorhinal area is illustrated in Figure 2, although this will be described in detail elsewhere (C. Köhler, unpublished observations). Well-known projections through the perforant and alvear pathways to the subiculum and 
Figure 2. A series of line drawings, ranging from ventral $(A)$ to dorsal $(E)$, illustrating the course and distribution of PHA-L-labeled axons in experiment 311 after an injection confined to the lateral entorhinal area. From horizontal sections. $A C B, \mathrm{~N}$. accumbens; $A L A$, anterior limbic area; $A O N$, anterior olfactory n.; $B L A$, basolateral n. amygdala; $B S T$, bed n. stria terminalis; $C A_{1,3}$, fields of Ammon's horn; $C e A$, central n. amygdala; $C P$, caudoputamen; $D B B$, n. diagonal band; $D G$, dentate gyrus; $G P$, globus pallidus; $I C$, islands of Calleja; $I G$, induseum griseum; $I M$, intercalated mass (amygdala); INS, insular region; $L A$, lateral $\mathrm{n}$. amygdala; $L E A$, lateral entorhinal area; $L H A$, lateral hypothalamic area; $L P O$, lateral preoptic area; $L S$, lateral septal $\mathrm{n}$; $M E A$, medial entorhinal area; $M e A$, medial $\mathrm{n}$. amygdala; $M O$, motor cortex; $M P N$, medial preoptic n.; $M S$, medial septal n.; $O B$, olfactory bulb; $O R B$, orbital cortex; $O T$, olfactory tubercle; $P A$, periamygdaloid area; $P A G$, periaqueductal gray; $P A R$, parasubiculum; $P E R I$, perirhinal area; $P I R$, piriform cortex; PLA, prelimbic area; PRE, presubiculum; $P R O$, prorhinal area; $P V H$, paraventricular n. hypothalamus; $R N$, red n.; $R S P$, retrosplenial area; $S H$, septohippocampal n.; $S I$, substantia innominata; $S N$, substantia nigra; $S S$, somatosensory area; $S U B$, subiculum; $T$, temporal region (including auditory area); $T T$, taenia tecta; $V L$, lateral ventricle; 17,18 , visual area; $a c$, anterior commissure; $b c$, superior cerebellar peduncle; $f x$, fornix; ic, internal capsule; igl, internal granular layer (olfactory bulb); lot, lateral olfactory tract; ot, optic tract; $s t$, stria terminalis.

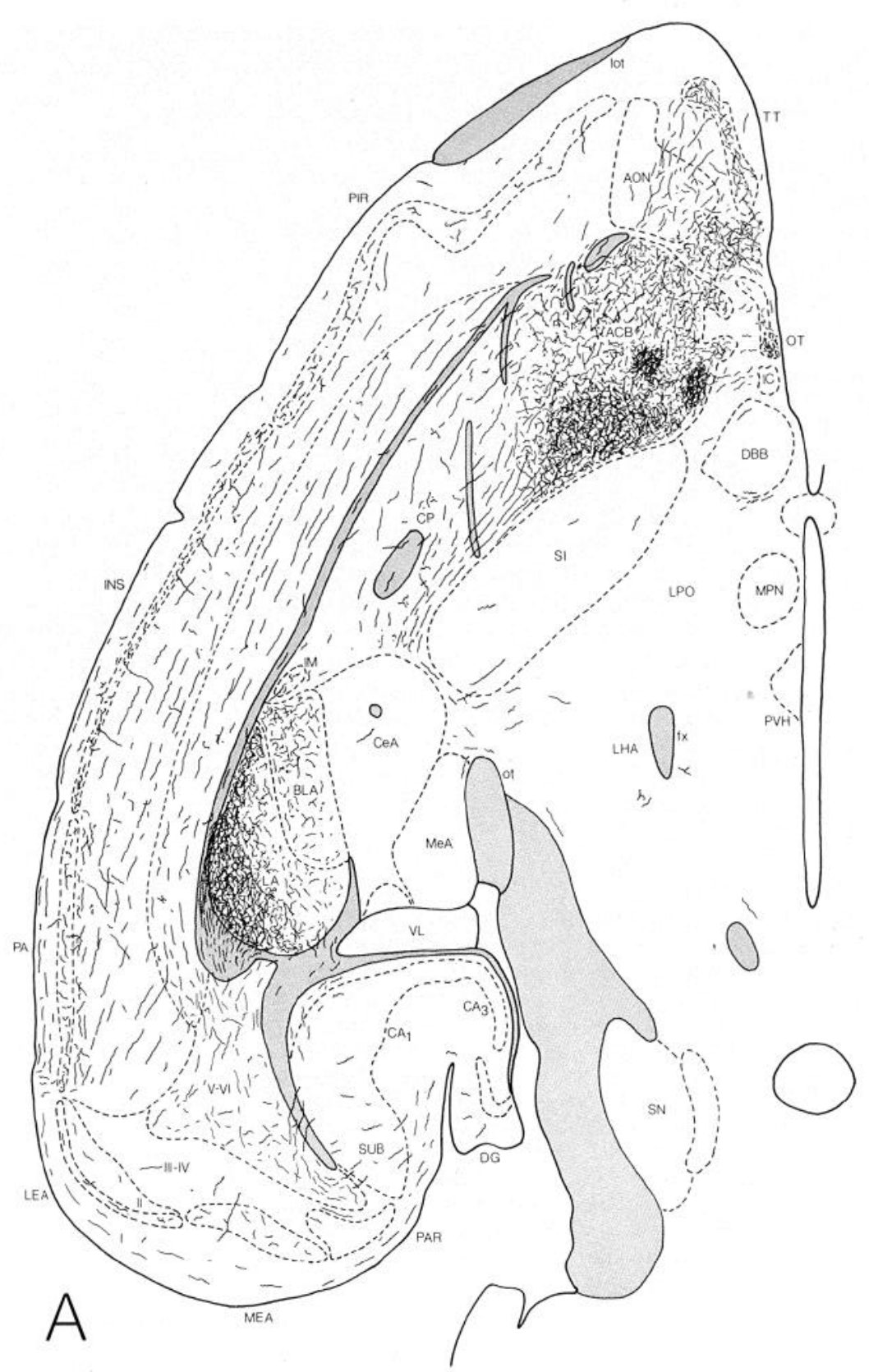

Ammon's horn (see Raisman et al., 1965; Steward, 1976; Swanson and Cowan, 1977) were heavily labeled, while only a few fibers were seen in the molecular layer of the dentate gyrus -a reflection of the fact that very few cells in layer II of the entorhinal area were labeled by the injection (see Steward and Scoville, 1976). In addition, labeled fibers were obvious in layers I, V, and VI of the pre- and parasubiculum, as well as in a restricted part of layer II centered between the medial tip of the medial entorhinal area and the parasubiculum. The anterior hippocampal rudiment, which consists of the induseum griseum dorsal to the corpus callosum and the taenia tecta rostral and ventral to it, also received a clear input from the lateral entorhinal area (Wyss, 1981).

Outside the hippocampal formation, at least some labeled fibers were found in the superficial (I and II) and deep (VI) layers of all parts of the cortical mantle, as well as in the internal granular layer of the olfactory bulb, although the density and precise distribution of fibers varied greatly in different areas
(Fig. 2). Ventral to the rhinal fissure (Fig. 2A), a moderate number of labeled fibers were found throughout the length of the piriform cortex, although they were more dense caudally in the periamygdaloid area. They were found in all 3 layers, although they were somewhat more dense in layer II and quite sparse in layer I. A similar, though considerably more dense, pattern was seen in the olfactory tubercle, although fibers appeared to avoid the islands of Calleja themselves. Many longitudinally oriented fibers coursed through the endopiriform nucleus deep into the piriform cortex, and through the dorsally adjacent claustrum deep into the insular region. Although all of these longitudinal fibers were varicose, very few gave rise to obvious terminal plexuses, and the extent to which they innervated cells in the claustrum (and its piriform component) is unclear. The cell layer of the anterior olfactory nucleus received a particularly dense plexus of labeled fibers (Fig. 3), which appeared to enter from both the nucleus accumbens (Fig. $2 A$ ) and adjacent cortical areas (Fig. $2 B$ ). Finally, the nucleus of the lateral olfactory tract 


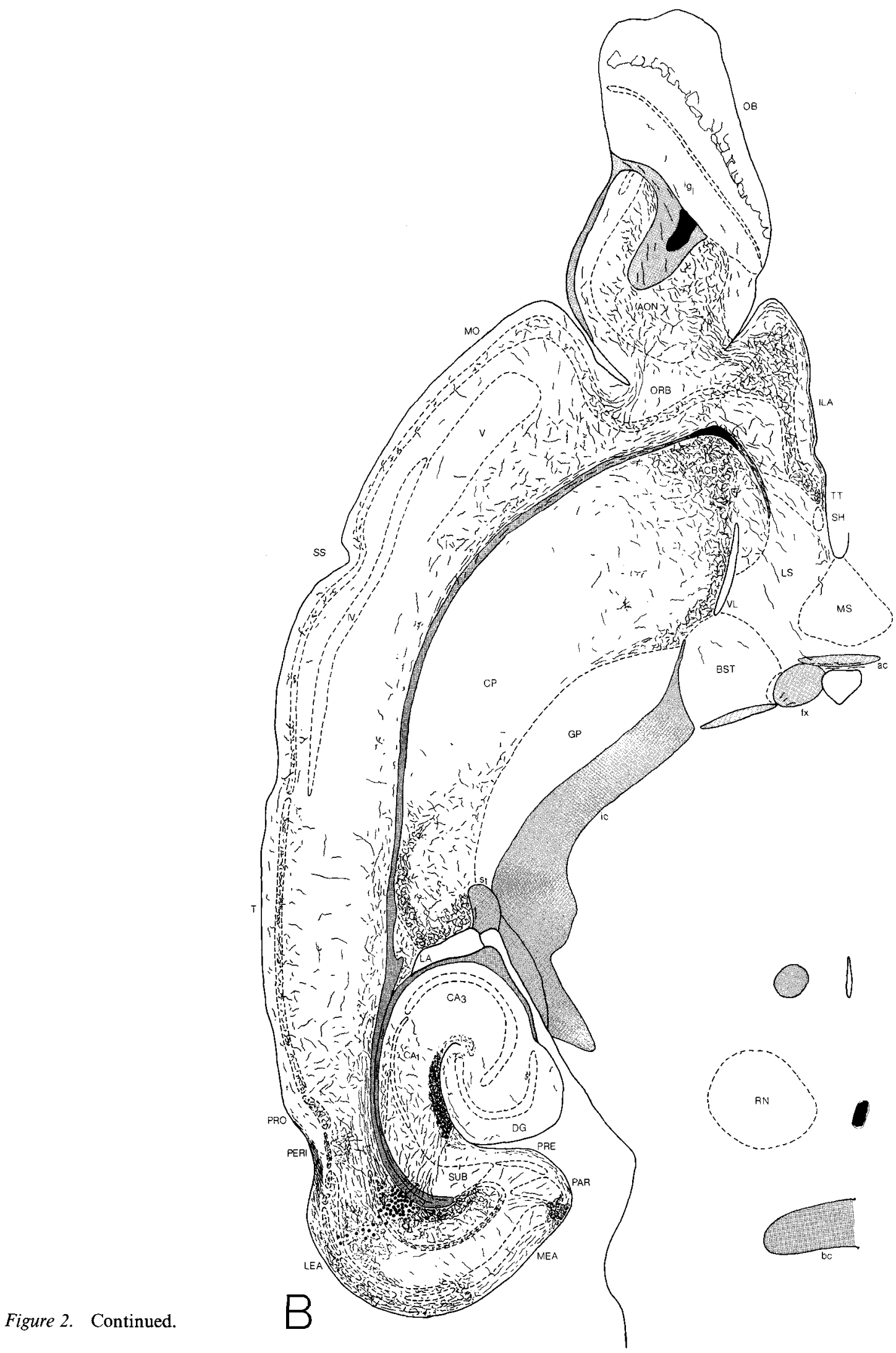

and the anterior cortical nucleus of the amygdala appeared to receive sparse inputs, whereas a dense plexus of fibers was clearly labeled in both the molecular and cellular layers of the posterior cortical nucleus of the amygdala and the amygdalo-hippocam- pal transition area (posterior medial nucleus of the amygdala; not illustrated).

By far the densest cortical terminal fields dorsal to the rhinal fissure were found in medial parts of the prefrontal region, in- 


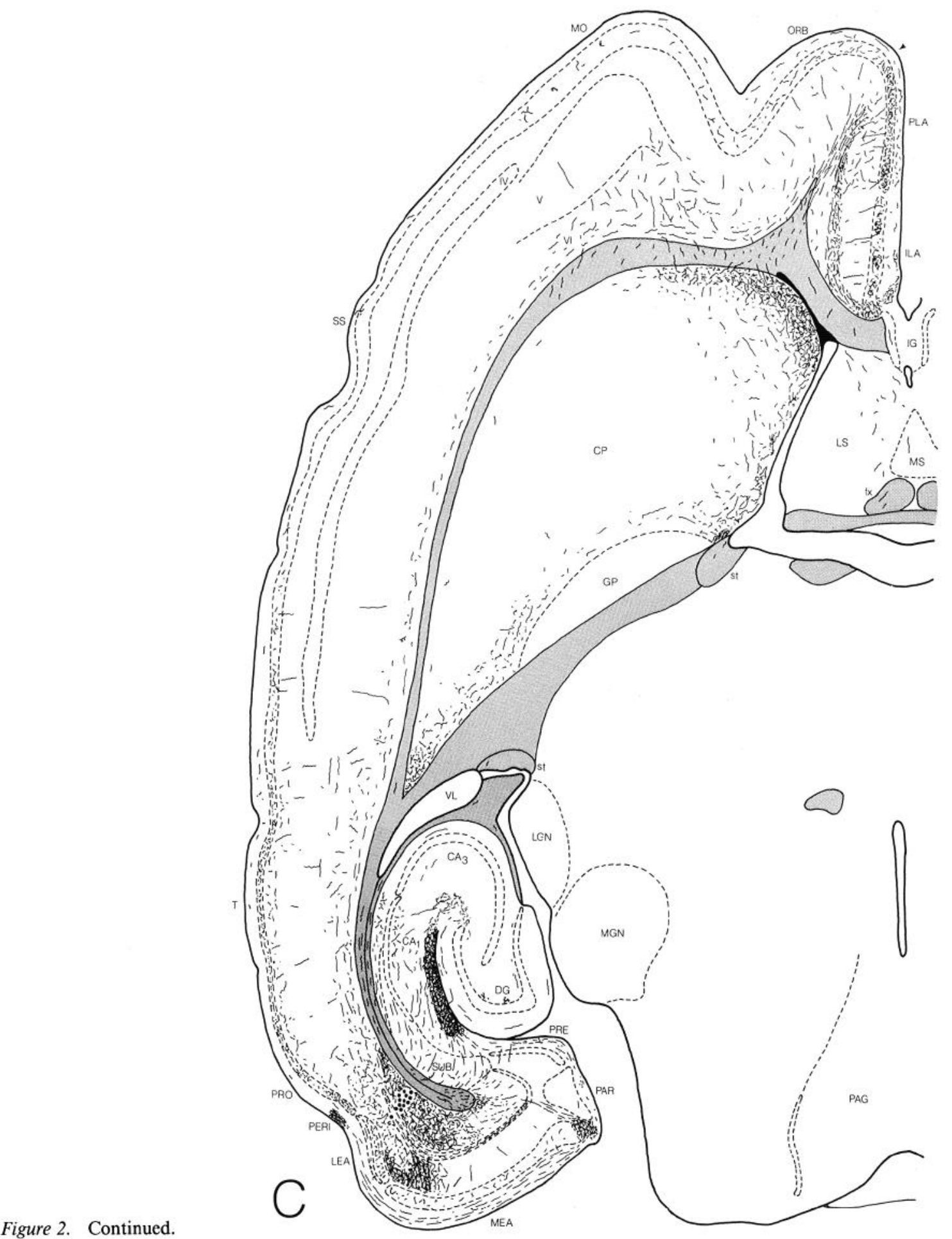

Figure 2. Continued.

cluding the infralimbic and prelimbic areas [the parcellation of Krettek and Price (1977) was used for the prefrontal and insular regions, while that of Vogt and Peters (1981) was used for the cingulate gyrus]. As is shown in Figures $2, B$ and $C, 3$, and $4 A$, dense terminal plexuses were labeled in layers II and $V$ of the infralimbic and prelimbic areas, and many fibers appeared to enter these layers from layer VI, and perhaps from layer I as well. Further caudally, layers II and VI of the anterior limbic area of the cingulate gyrus appeared to receive a modest input, while, somewhat surprisingly, the retrosplenial area caudal to it received perhaps the sparsest input from the lateral entorhinal area of any cortical field. Proceeding rostrally again, we find that the orbital cortex of the prefrontal region and the entire length of the insular region received a relatively uniform complement of fibers that was concentrated in layers II and VI and was only moderately dense.

The somatosensory area contained only scattered fibers, which were found primarily in layers II and VI (Fig. $4 \mathrm{C}$ ), although the density of labeled axons was noticeably greater in caudal parts of this area (Fig. 2). In the occipital region, the primary visual 


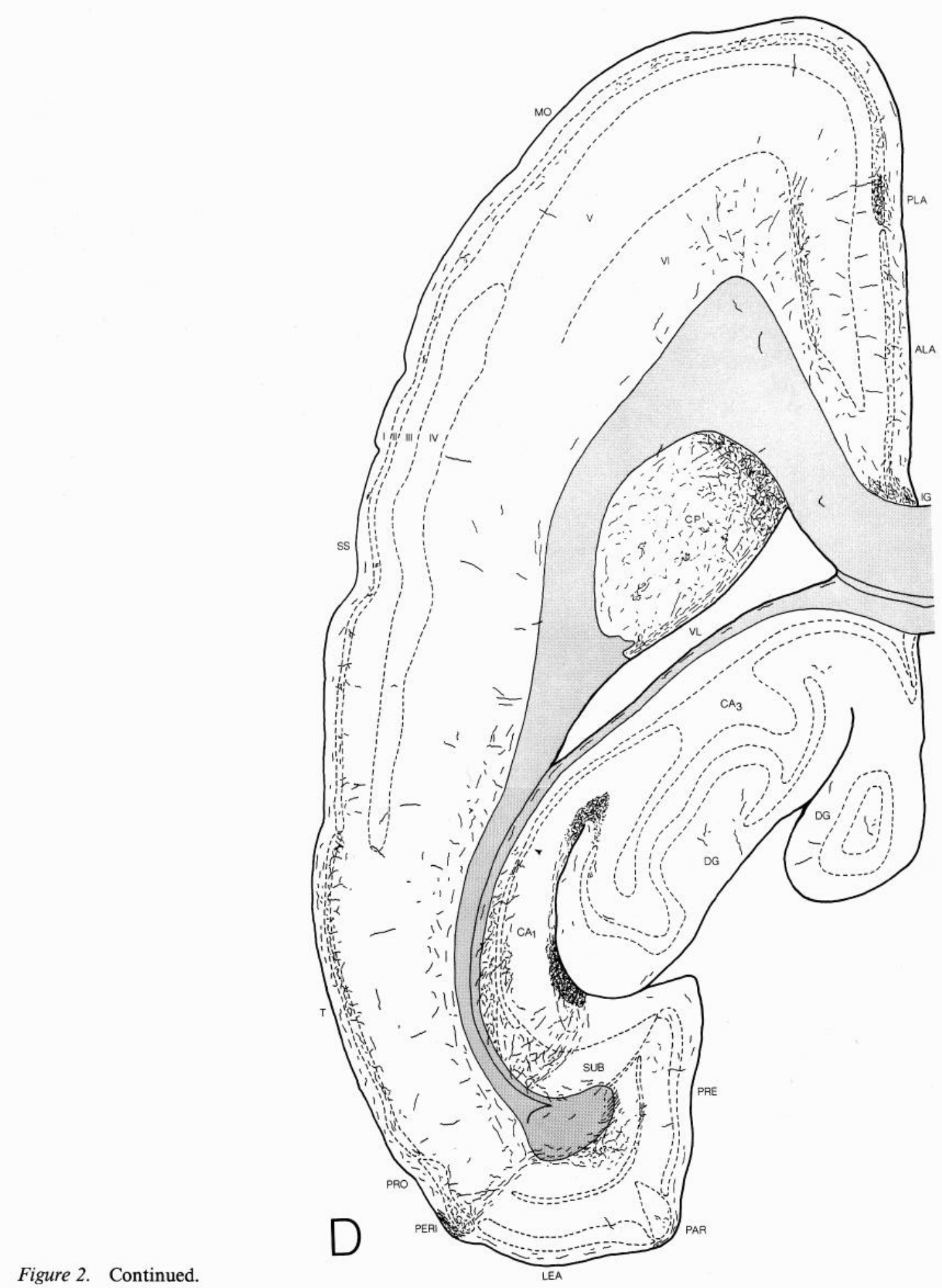

area 17 contained a sparse-to-moderate number of fibers in layers II and VI, as well as a larger number of fibers in the deeper parts of layer I, a feature that distinguished it from the surrounding area 18 (Fig. $2 E$ ). Although the auditory cortex of the rat has never been carefully parcelated, on cytoarchitectonic and electrophysiological grounds, the entire temporal region received a substantial complement of labeled fibers that was generally centered in the deep part of layer I, as well as in layers II, III, and VI (Fig. 4B). This pattern extended ventrally into the prorhinal area (area 36 ), as well as into the perirhinal area (area 35), which displayed a characteristic, very dense plexus of fibers in the superficial quarter of layer I (Fig. 2, $A-C$ ).

The motor cortex also received fibers that were distributed in a characteristic way. Here, layer VI contained a relatively larger number of fibers coursing in all directions, whereas only a few labeled fibers were observed in layer II (and layer I).

Two subcortical regions of the telencephalon also contained massive plexuses of labeled fibers after PHA-L injections in the lateral entorhinal area. One was centered along the length of the medial striatum, and included parts of the caudoputamen, as 


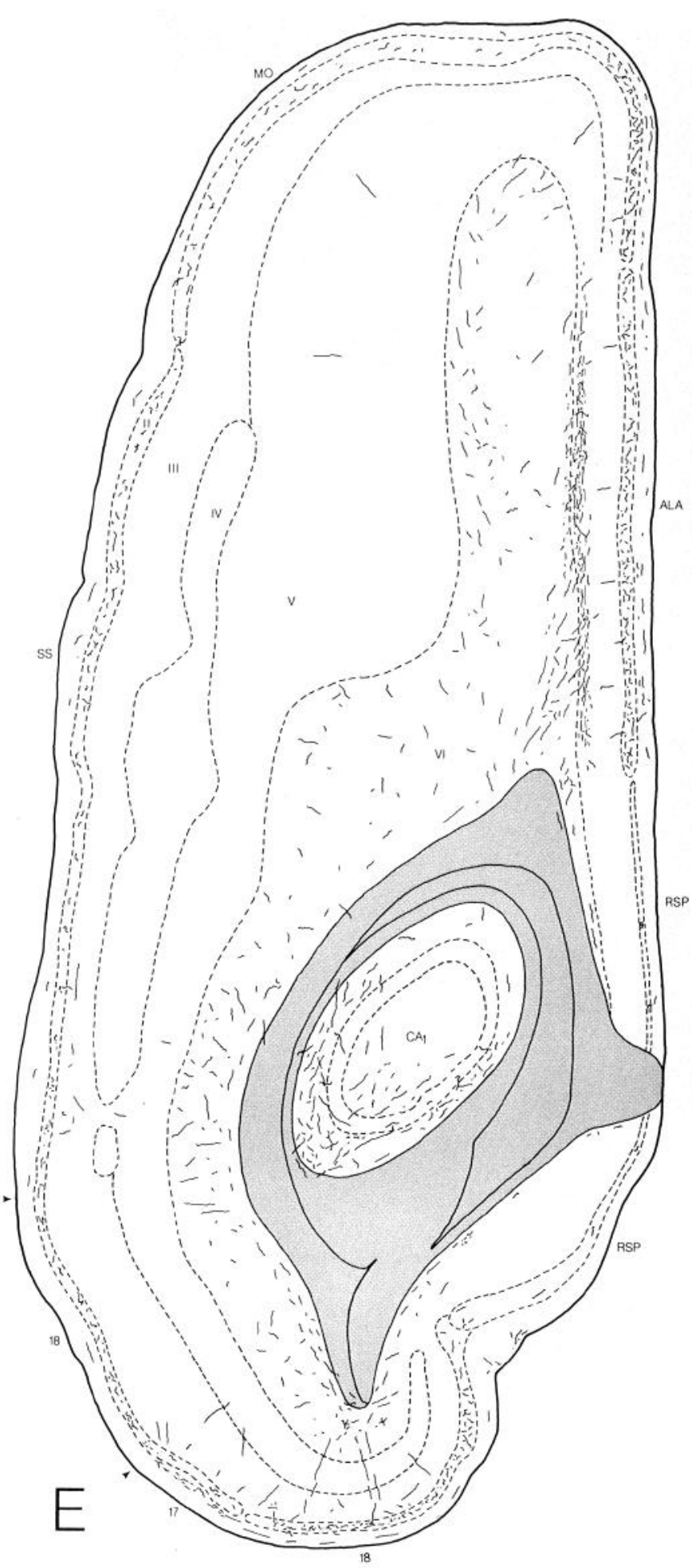

Figure 2. Continued.

well as most of the nucleus accumbens (Figs. 2, $A-D ; 3$ ); the other involved the lateral and basolateral nuclei of the amygdala. A very small number of fibers were also observed in the lateral and medial septal nuclei, and a few were even seen crossing the midline in and near the anterior commissure (Fig. 2C).

Only a very few labeled axons were observed in the diencephalon; they were most often found in the lateral hypothalamic area and in the paraventricular nucleus of the thalamus.

Two other features of the telencephalic projection from the lateral entorhinal area deserve comment. First, a similar pattern

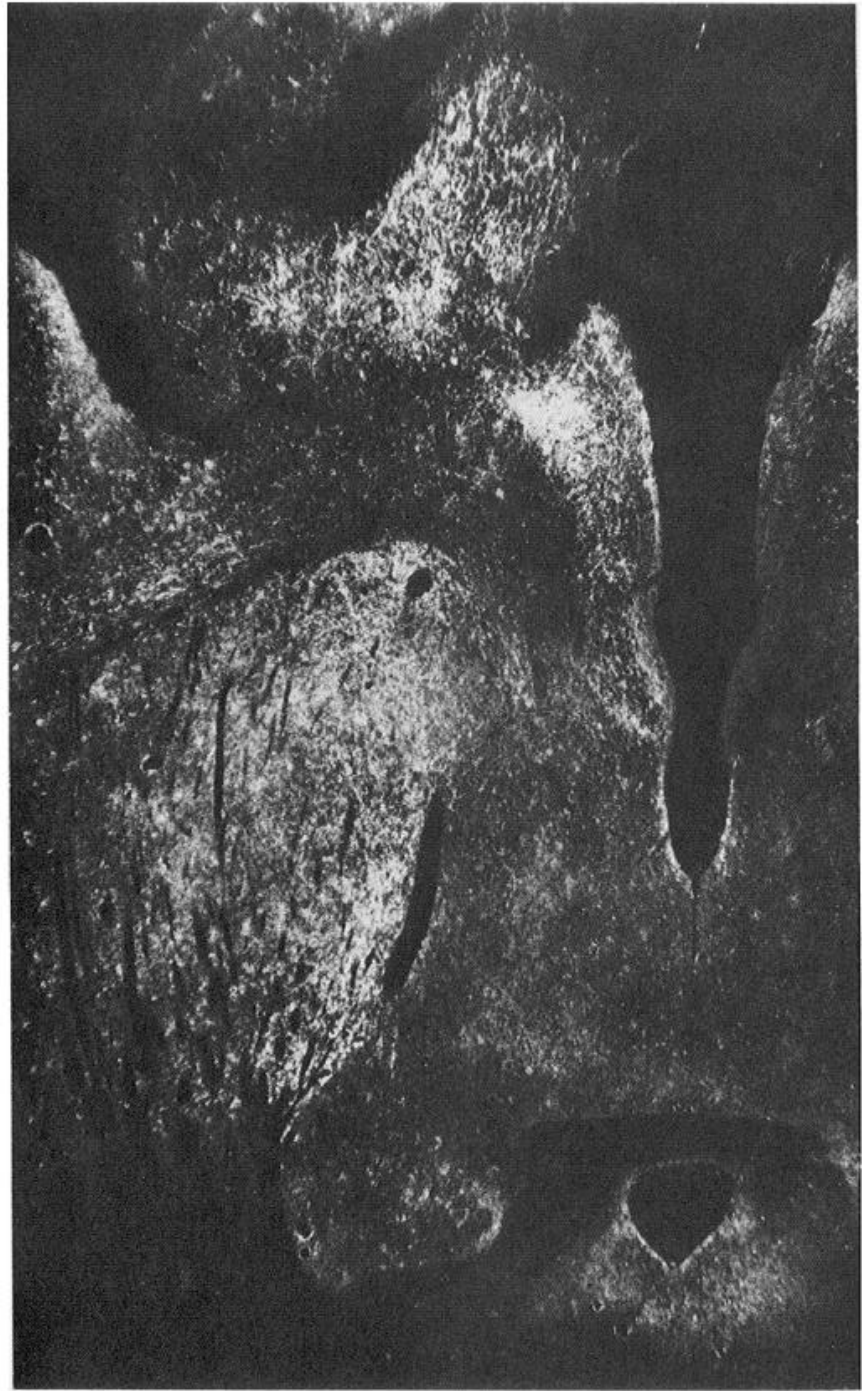

Figure 3. A low-power dark-field photomicrograph illustrating the general appearance of PHA-L-labeled axons (white) in the prefrontal cortex, olfactory peduncle, and striatum of experiment 311 . The level of this photomicrograph corresponds to that illustrated schematically in Figure $2 B . \times 20$.

of labeled fibers was observed on the side of the brain opposite the injection site, although it was very much less dense than that on the ipsilateral side (e.g., Fig. $4 A$ ). The fibers appeared to reach the contralateral side by coursing through the dorsal hippocampal and anterior commissures. Second, the course taken by fibers from the lateral entorhinal area to particular cortical fields was not always clear, and will require experimental clarification. It is clear from our material that many fibers course rostrally through the external capsule and the claustrum, but it is also quite possible that fibers reach some cortical areas by way of layers I and/or VI in adjacent areas. Finally, it is clear that fibers reach some areas, particularly in frontal regions, by passing through the external capsule from the striatum (Fig. $2 C$ ).

\section{Retrograde transport experiments}

A limited number of experiments $(n=8)$ with the retrograde tracer fast blue were carried out to confirm in a general way, with a different technique, that fibers from the lateral entorhinal area reach widespread parts of the cortical mantle. While the results of these experiments cannot prove the existence of terminals within the injection site because the tracer is incorpo- 

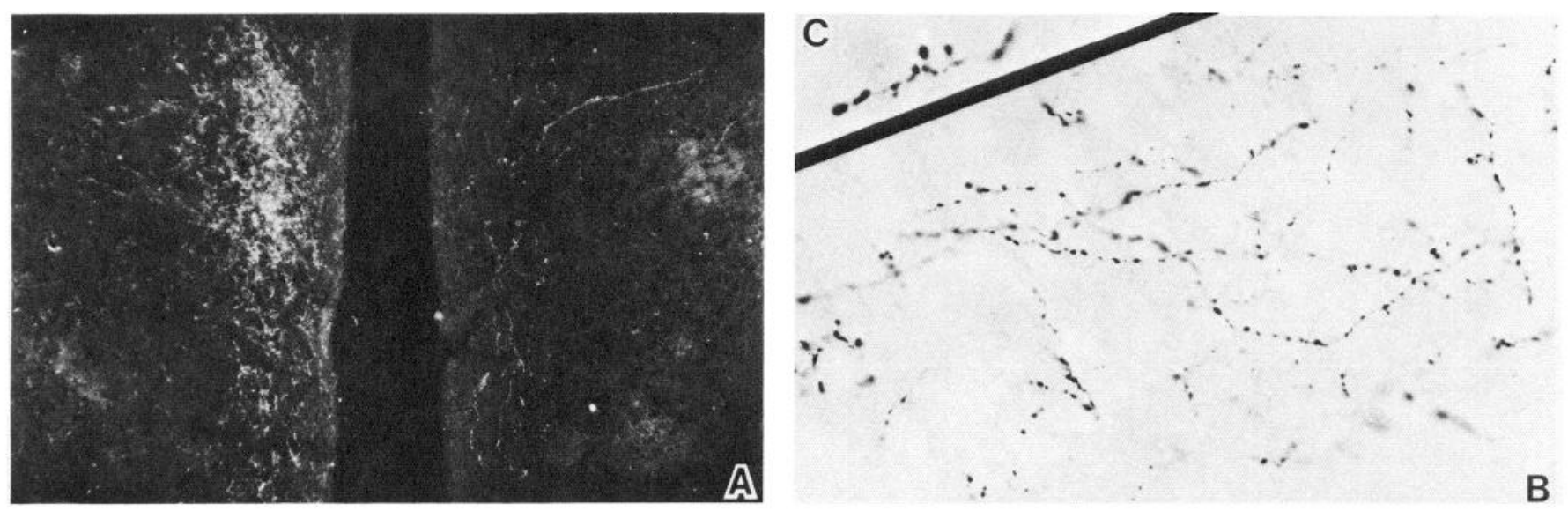

Figure 4. A, PHA-L-labeled fibers concentrated in layer II of the infralimbic area on the side ipsilateral (left) and contralateral (right) to an injection site in the lateral entorhinal area. Dark-field illumination, $\times 50 . B$, PHA-L-labeled fibers in layer II of presumed auditory areas of the temporal region. Bright-field illumination, $\times 300$. $C$, High-power photomicrograph of a PHA-L-labeled axon in layer VI of the somatosensory area; note several terminal boutons arising from this varicose axon. Bright-field illumination, $\times 800$.

rated by fibers of passage (Sawchenko and Swanson, 1981), they are useful in identifying the laminar distribution of neurons projecting to or through the injection site.

For these experiments, injections of the tracer were centered in the region of the infralimbic and prelimbic areas, the somatosensory area, the motor area, and the auditory area (Fig. 5). As is shown in Figure 6, each injection led to the retrograde labeling of cells in the lateral entorhinal area, and in all experiments the densest labeling was found in layer IV (see also Van Hoesen, 1982). There were also striking differences in the laminar distribution of retrograde labeling when different cortical areas were injected, although, because of the limited number of experiments, it is unclear how significant these differences are. Nevertheless, it may be useful to place the following observation on record. The most extensive retrograde labeling was obtained after injections centered in auditory parts of the temporal region (see 503 in Figs. 5 and 6, which spreads to the caudal part of the somatosensory area but involved only the deepest layers of the cortex); in these cases, retrograde labeling was observed in layers II-VI throughout the dorsoventral extent of the lateral entorhinal area, as well as in layers IV and VI of the medial entorhinal area and in the superficial half of the pyramidal layer of the subiculum. In sharp contrast, injections confined to the somatosensory area (see 608 in Figs. 5 and 6, where the injection site invaded all 6 layers) retrogradely labeled neurons confined to layer IV of the lateral entorhinal area. Similar injections in the motor area (423 in Figs. 5 and 6) retrogradely labeled neurons in layers IV and VI of the lateral entorhinal area (Fig. $7 B$ ) and, to a lesser extent, in the medial entorhinal area as well. And finally, injections that labeled medial (and perhaps orbital) parts of the prefrontal region (422 in Figs. 5 and 6) led to extensive labeling of neurons in layers II, IV, V, and VI of the lateral (Fig. 7A) and medial entorhinal areas, as well as in restricted superficial parts of the pre- and parasubiculum and in the pyramidal layer of the subiculum.

Finally, 3 combinations of double retrograde tracer experiments with 1 label in the medial prefrontal cortex and another in the dentate gyrus and Ammon's horn (see Materials and Methods) were carried out, and at least 1 experiment with each of the 3 combinations of tracers produced extensive retrograde labeling for each tracer in the lateral entorhinal area. No evidence of doubly labeled neurons in any layer of the lateral (or medial) entorhinal area was obtained in any of the 6 experiments, even though many singly labeled neurons with either tracer were observed (Fig. $7 C$ ).

\section{Discussion}

The results of the present study suggest that neurons in the lateral entorhinal area innervate all parts of the cortical mantle, as well as medial parts of the striatum and the basolateral complex of the amygdala. Before discussing the implications of this finding, however, it is important to consider the validity of the methods upon which it is based.

It seems clear from our results that fibers from the lateral entorhinal area at least reach all parts of the cortical mantle. The anterograde tracer PHA-L does not appear to be taken up in detectable amounts by fibers of passage (Gerfen and Sawchenko, 1984), and our injection sites did not label cells outside the limits of the lateral entorhinal area. Furthermore, injections of the retrograde tracer fast blue into a representative sample of cortical regions all labeled neurons in the lateral entorhinal area.

Nevertheless, our results do not prove unequivocally that fibers from the lateral entorhinal area innervate, or establish synaptic contacts within, all parts of the cortical mantle; this must be established at the ultrastructural level. However, it should be pointed out that at least some terminal boutons (Fig. $4 C$ ) were observed in all areas, and these structures have invariably been shown to form synaptic contacts wherever they have been examined ultrastructurally (see Rockel and Jones, 1973; Wouterlood and Groenewegen, 1985).

With these reservations in mind, our results confirm that the lateral entorhinal area projects through the perforant and alvear paths to the dentate gyrus and hippocampus, as well as to all parts of the olfactory cortex, cingulate gyrus, medial prefrontal region, and perirhinal and insular regions (see the introduction).

We have also confirmed that the lateral entorhinal area projects to medial parts of the caudoputamen (Sorensen and Witter, 1983), the nucleus accumbens (Krayniak et al., 1981), and the basolateral complex of the amygdala (Ottersen, 1982; Wyss, 1981). In addition, however, our results suggest that the efferent projections of the lateral entorhinal are even more widespread than this, and that they may in fact reach all parts of the cortical mantle, although the density and laminar distribution of these pathways varies from one area to another.

It is not entirely clear why this widespread distribution of fibers has not been observed in previous studies, although the PHA-L method has revealed considerably more widespread projections in other systems as well, particularly in the supramammillary projection to the hippocampal formation (Haglund 


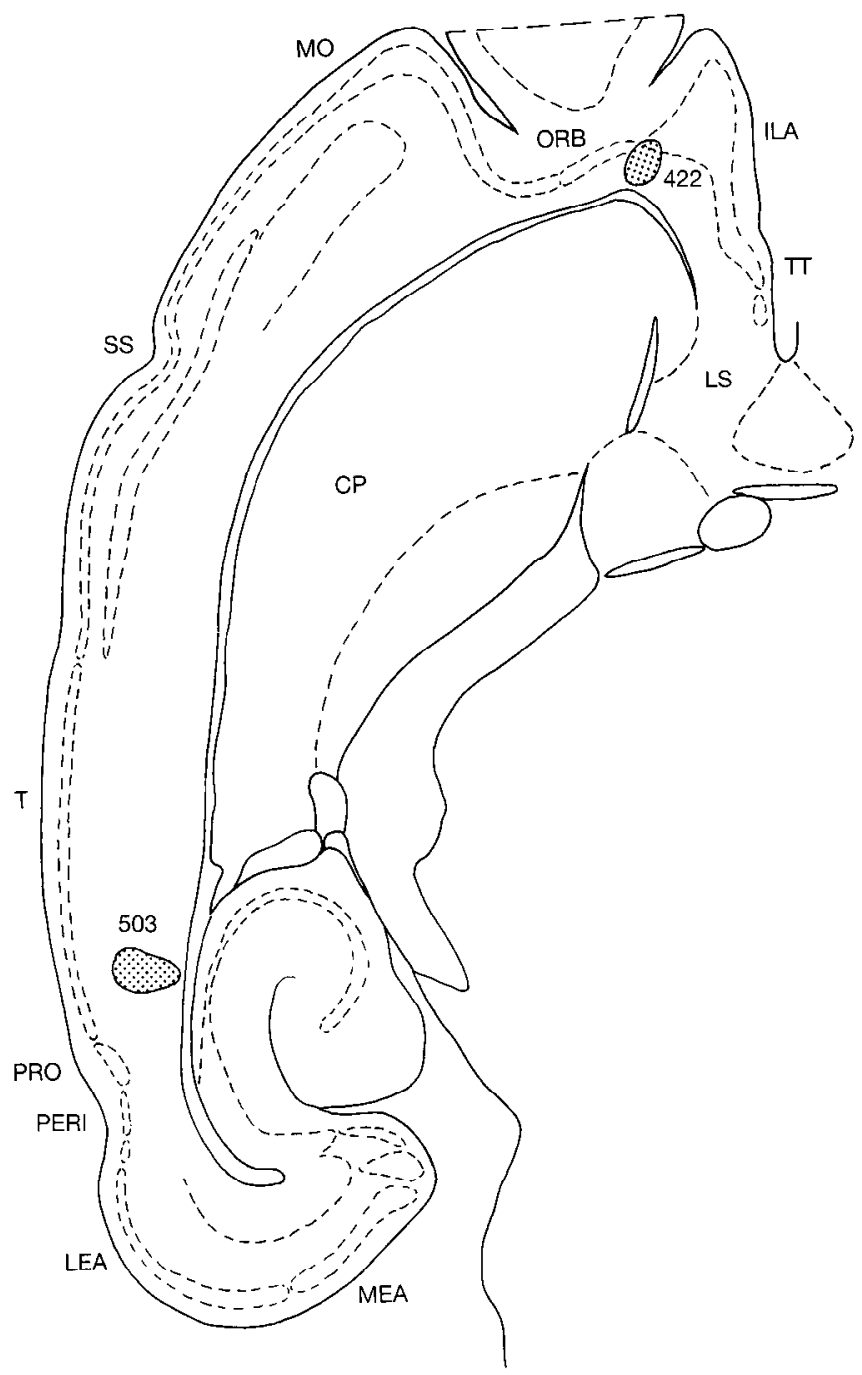

Figure 5. The location of key fast blue injection sites (shading) is illustrated in this series of drawings. See legend to Figure 2 for abbreviations.

et al., 1984). In both cases, when comparisons of anterogradely labeled pathways are made between the autoradiographic and PHA-L methods, it is clear that scattered fibers are difficult to detect autoradiographically because a low density of silver grains cannot be distinguished confidently from background levels.

Our results, as well as those of others (Sorensen, 1985; Wyss, 1981), also indicate that the efferent projections of the medial part of the entorhinal area are not as extensive as those from the lateral part. This is of interest for 2 reasons. First, the lateral part is more highly differentiated than the medial part with respect to cytoarchitectonic lamination. Thus, layer II can be divided into 2 distinct bands, and layer IV is more obvious, in the lateral entorhinal area (see Blackstad, 1956). And second, afferent projections entering the 2 parts of the entorhinal area differ in several important ways. The most obvious difference lies in the fact that the pre- and parasubiculum project massively to the medial but not the lateral entorhinal area (Köhler, 1984, 1985; Köhler et al., 1978; Shipley, 1975). Thus, neocortical association area projections to the pre- and parasubiculum (see the introduction) are relayed through the medial perforant path to middle parts of the dentate gyrus molecular layer and to Ammon's horn, but do not appear to be in a position to influence directly the projections of the lateral entorhinal area to the rest of the cortical mantle. However, they may do so less directly

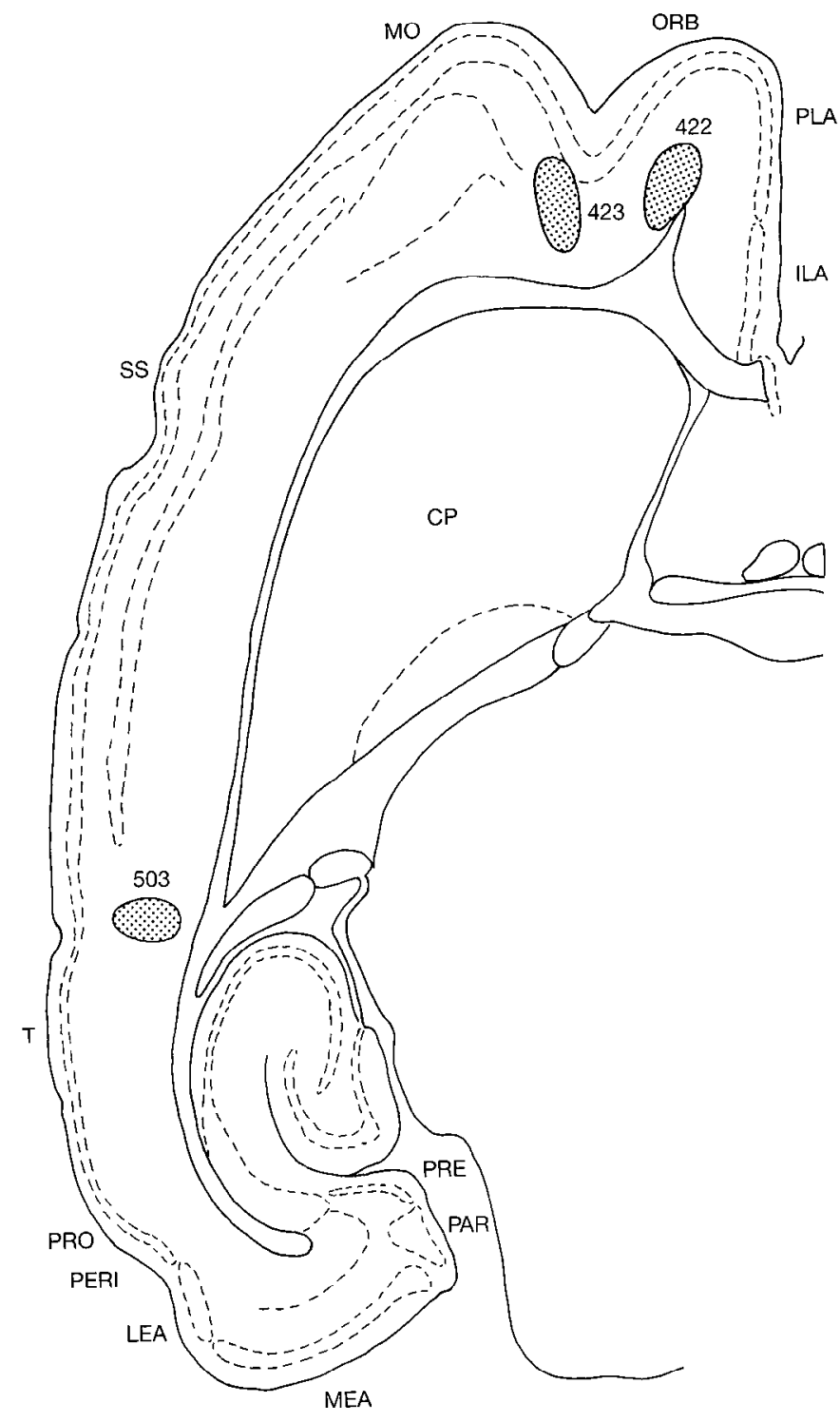

Figure 5. Continued.

after passing through the trisynaptic circuit, because the subiculum proper, which receives a massive input from field $\mathrm{CA}_{1}$ (Hjorth-Simonsen, 1973; Swanson and Cowan, 1977), projects to both the medial and lateral parts of the entorhinal area (Rosene and Van Hoesen, 1977; Shipley and Sorensen, 1975; Sorensen and Shipley, 1979; Swanson and Cowan, 1977), as does field CA $\mathrm{CA}_{1}$ itself (Swanson and Cowan, 1977).

Direct telencephalic neural inputs to the lateral entorhinal area have been reported from the main olfactory bulb and piriform cortex (Carlsen et al., 1982; Haberly and Price, 1978a, b; Kosel et al., 1981; Krettek and Price, 1977), which end in the superficial part of layer I; the periamygdaloid cortex (Krettek and Price, 1977), which ends in layer II; the lateral nucleus of the amygdala (Krettek and Price, 1977), which ends in layer III; parts of the inferior temporal gyrus and orbitofrontal region (Van Hoesen and Pandya, 1975a, b; Van Hoesen et al., 1975), which end in layers I-III; the prelimbic area and insular region (Beckstead, 1979; Saper, 1982), which end predominantly in the deeper layers; the medial septal-diagonal band complex, which ends in all layers (Mellgren and Srebro, 1973); and the claustrum (Beckstead, 1978). Thus, the lateral entorhinal area appears to receive direct inputs from what are usually regarded 


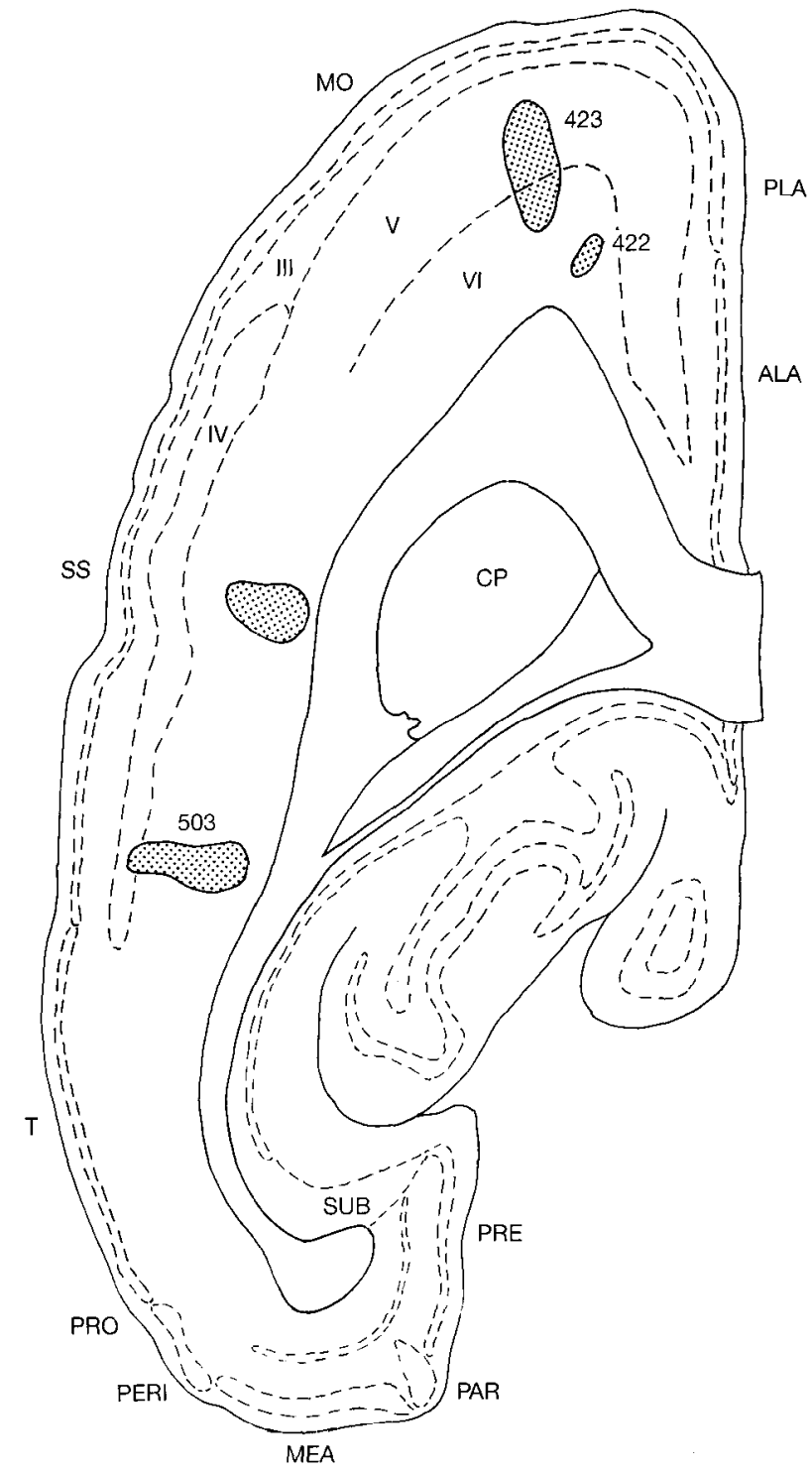

Figure 5. Continued.

as multimodal association areas, from olfactory cortex, from the amygdala and septal region, and from the claustrum.

In addition, retrograde tracer studics (Wyss ct al., 1979) indicate that a wide variety of cell groups in the diencephalon and brain stem project to the entorhinal area as a whole, although not all of these have been characterized with anterograde tracer methods. It is known, however, that the nucleus reuniens of the thalamus projects to layers I and III of the lateral entorhinal area (Herkenham, 1978), while $\alpha$-MSH-stained cells in the lateral hypothalamic area (Köhler et al., 1984) and other cells in the supramammillary nucleus (Haglund et al., 1984) send fibers to all layers of this region. In addition, dopaminergic neurons in the midbrain ventral tegmental area end in all layers of the rostral lateral entorhinal area, where they form patches in layer I (Hökfelt et al., 1974). Since the medial septal-diagonal band complex, lateral hypothalamic area, supramammillary nucleus, and ventral tegmental area are all thought to receive massive inputs from the medial forebrain bundle, it seems likely that cells in these regions may also relay a broad variety of information to the lateral entorhinal area that is perhaps related to attention or arousal (see Haglund et al., 1984; Köhler et al., 1984; Swanson, 1982; Swanson and Cowan, 1979).

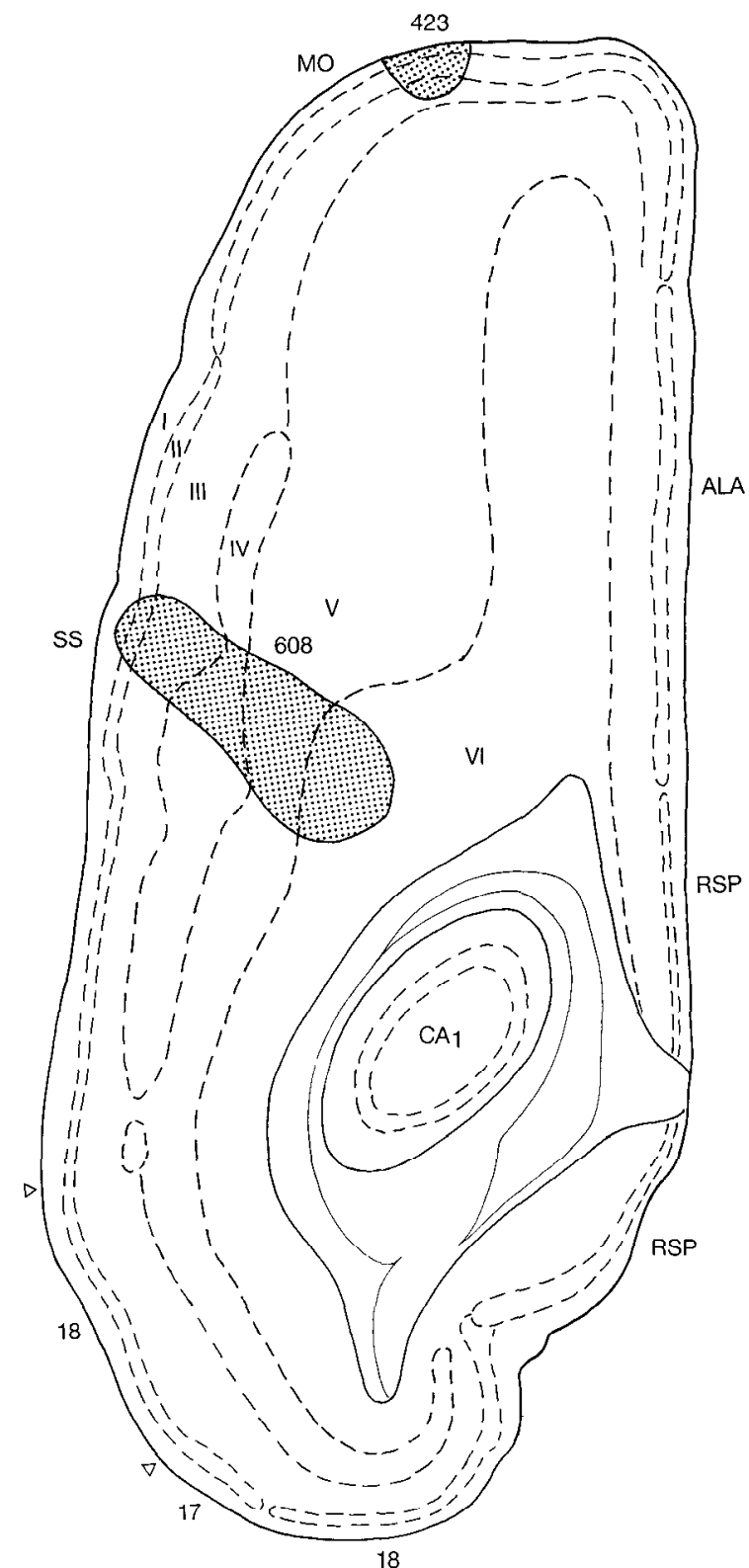

Figure 5. Continued.

In a general way, then, our results and those of others indicate that the lateral entorhinal area receives a wide range of information from many parts of the telencephalon, diencephalon, and brain stem and that it, in turn, projects back to the entire cortical mantle, as well as to the basolateral complex of the amygdala and medial parts of the striatum. The precise functional significance of these results is unclear at this time, but they do raise several interesting possibilities for future work. First, evidence that information processing in the hippocampal formation can influence directly all parts of the cortical mantle by way of the entorhinal area is intriguing in view of evidence that the hippocampal formation plays an important role in learning and memory (see the introduction). However, the precise cellular organization of this remarkably extensive association (and less dense commissural) projection is not known. At the very least, our results indicate that each small PHA-L injection in a different part of the lateral entorhinal area labeled fibers throughout the cortical mantle. Therefore, the projection does not appear to be organized in an obviously topographical way. On the other hand, double retrograde tracer experiments 


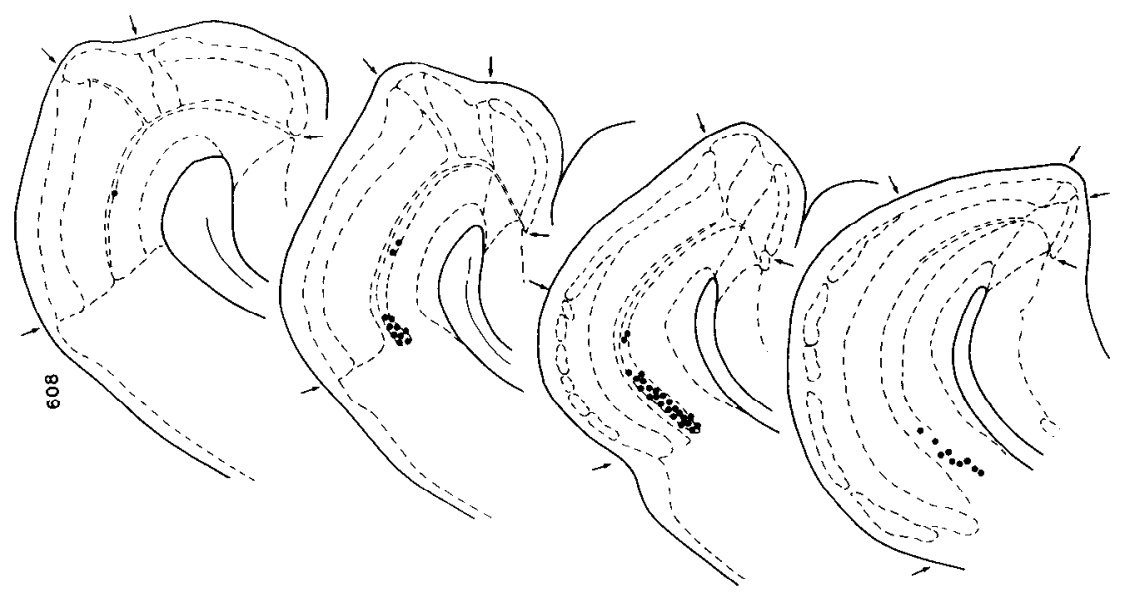

Figure 6. A series of line drawings showing the distribution of retrogradely labeled neurons (dots) in and near the entorhinal area after the fast blue injections illustrated in Figure 5. Injection sites: 423 , rostral motor cortex; 422, medial prefrontal region; 503 , temporal region (including auditory cortex) and caudal tip of somatosensory area; 608 , somatosensory area. For each experiment a series of 4 horizontal levels is illustrated, from dorsal (left) to ventral (right). $a b$, Angular bundle; $E N T_{l, m}$, lateral and medial entorhinal areas; $l d$, lamina dissicans; $P A R$, parasubiculum; $P R E$, presubiculum; $S U B$, subiculum.
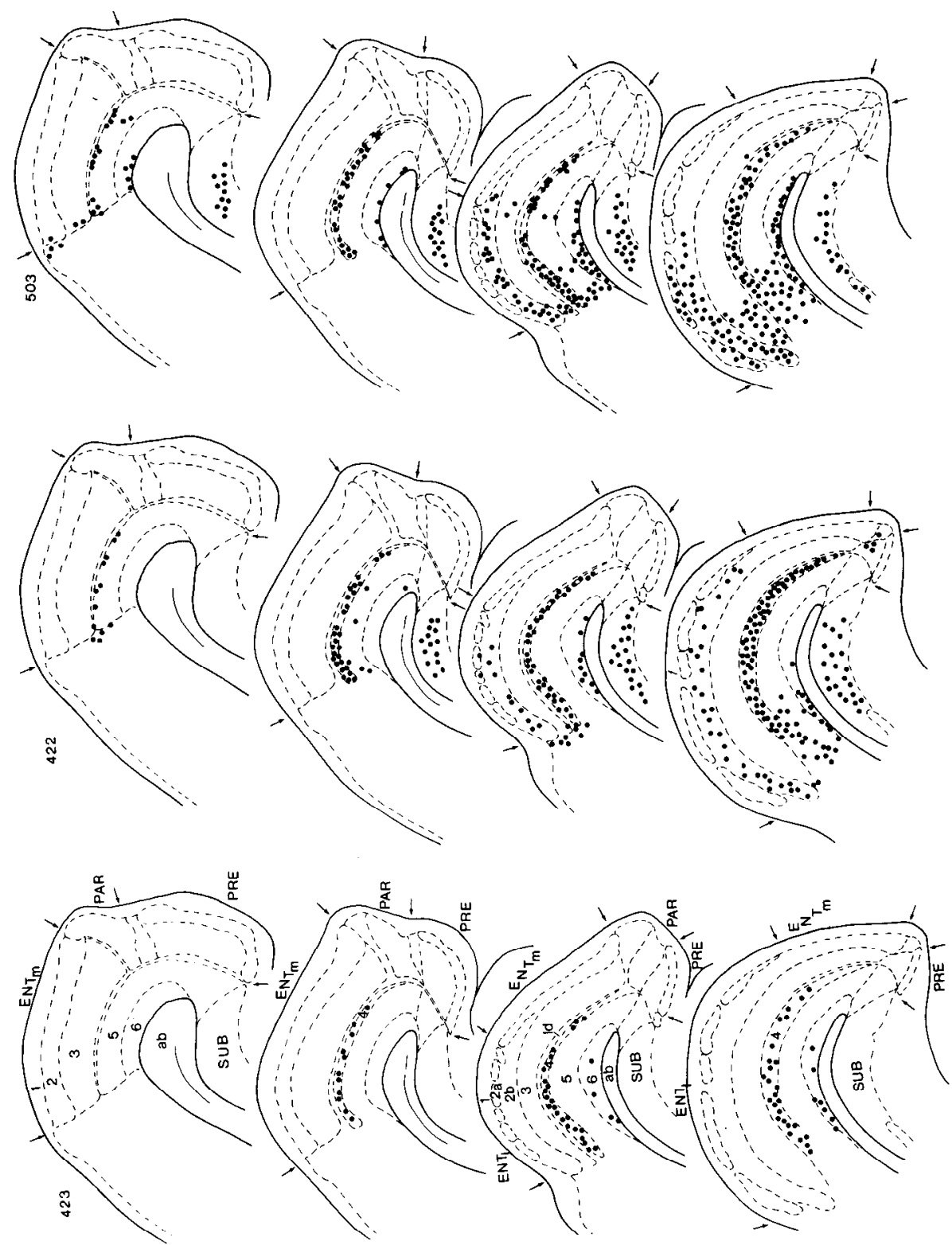

suggest that projections from the lateral entorhinal area to 2 distinct terminal fields-the medial prefrontal cortex and the hippocampus and dentate gyrus - arise from essentially separate groups of neurons. The extent to which separate groups of neu- rons in the lateral entorhinal area project to other cortical (and subcortical) areas of the telencephalon remains to be determined, as, of course, docs the complement of neural inputs to these particular groups of cells in the lateral entorhinal area. 

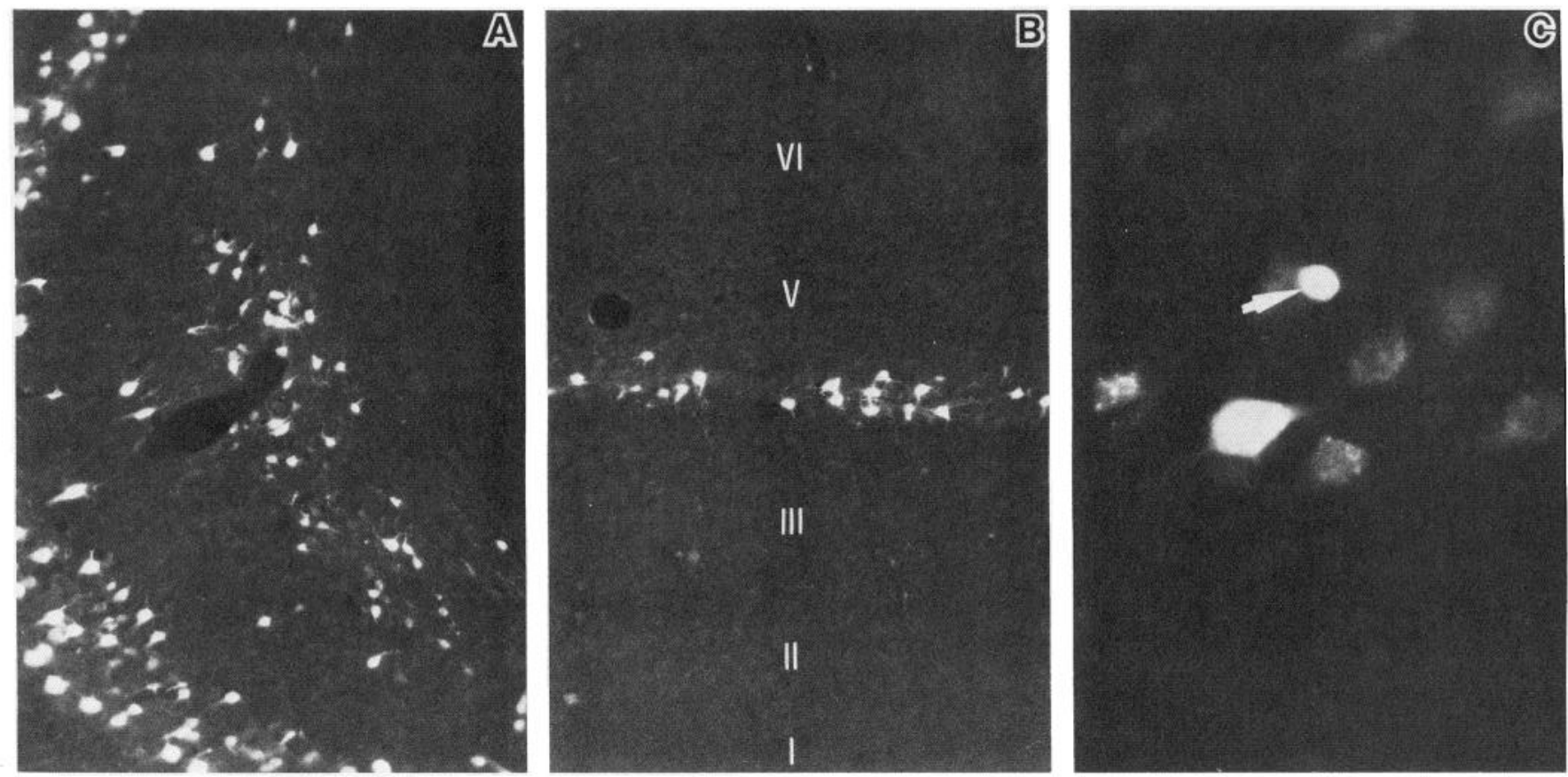

Figure 7. A, Retrogradely labeled neurons in the entorhinal area after an injection of fast blue centered in the medial prefrontal region. Note that cells are concentrated in layer II (left) and the deeper layers (middle). This horizontal section is from experiment 503, which is illustrated schematically in Figure 6. B, Retrogradely labeled neurons confined to layer IV of the lateral entorhinal area following an injection of fast blue into the motor area; see Figure 6, experiment 423. $\times 125$. C, A high-power photomicrograph to show the appearance of retrogradely labeled neurons in layer II of the lateral entorhinal area, following injections of fast blue into Ammon's horn (labeled perikarya) and diamidino yellow (labeled nucleus, arrow) in the medial prefrontal region of the same animal. No evidence of doubly labeled neurons was obtained in any of the experiments involving the injection of two labels. When observed in the fluorescence microscope, labeled nuclei appear yellow and labeled perikarya appear blue, after UV excitation wavelengths are used. $\times 600$.

Second, it is clear that the lateral entorhinal area also projects to the lateral and basolateral nuclei of the amygdala (see also Wyss, 1981), and it has been shown that the lateral nucleus projects, in turn, back to layer III of the lateral entorhinal area (Krettek and Price, 1977). These bidirectional pathways between the lateral entorhinal area and the basolateral complex are of interest in the present context because recent evidence in the monkey indicates that the latter also has direct projections to widespread regions of the cortical mantle (Amaral and Price, 1984). Therefore, 2 regions of the telencephalon that may each innervate virtually the entire cortical mantle are themselves interconnected. This brings to mind the evidence that combined lesions of the amygdala and hippocampal formation in the monkey appear to result in considerably more profound memory deficits than do lesions involving either structure alone (Mishkin, 1978).

Third, our confirmation that the lateral entorhinal area projects massively to the nucleus accumbens and medial caudoputamen is of interest because this pathway suggests one route through which the hippocampal formation may influence locomotor activity. It has been shown that during exploratory sniffing behavior in the rat, the vibrissae move to and fro about $7 \times$ each second, and that this movement shows a 1-to-1 correlation with the hippocampal theta activity (Komisaruk, 1970). Furthermore, it now seems clear that the nucleus accumbens plays an important role in the initiation of locomotor activity (Kelly et al., 1975; Pijnenburg and Van Rossum, 1973), which is mediated, at least in part, by a series of descending pathways that synapse first in a subpallidal region including the substantia innominata (ventral pallidum) and lateral preoptic area (see Mogenson et al., 1983), which in turn project to what have been referred to as the subthalamic and mesencephalic locomotor regions (Brudzynski and Mogenson, 1985; Mogenson et al., 1985; Swanson et al., 1984).

Finally, it is worth emphasizing that there may be important species differences in the organization of pathways between the entorhinal area and the rest of the cortical mantle, although, as more sensitive tracing methods are applied to this problem, it would appear that major differences in general organizing principles are becoming less apparent. On the basis of the evidence presented here and elsewhere (see, for example, Haglund et al., 1984; Swanson et al., 1981), it seems clear that the PHA-L method and the retrograde tracers fast and true blue provide considerably more sensitivity than the autoradiographic and HRP methods. Systematic comparative studies with the newer tracers are now needed to clarify the organization of hippocampal-neocortical pathways in different species.

\section{References}

Amaral, D. G., and J. L. Price (1984) Amygdalo-cortical projections in the monkey (Macaca fascicularis). J. Comp. Neurol. 230: 465496.

Amaral, D. G., R. Insausti, and W. M. Cowan (1983) Evidence for a direct projection from the superior temporal gyrus to the entorhinal cortex in the monkey. Brain Res. 275: 263-277.

Andersen, P., T. V. P. Bliss, and K. K. Skrede (1971) Lamellar organization of hippocampal excitatory pathways. Exp. Brain Res. 13: 222-238.

Beckstead, R. M. (1978) Afferent connections of the entorhinal area in the rat as demonstrated by retrograde cell-labeling with horseradish peroxidase. Brain Res. 152: 249-264.

Beckstead, R. M. (1979) Autoradiographic examination of corticortical and thalamocortical projections of the mediodorsal projection (prefrontal) cortex in the rat. J. Comp. Neurol. 184: 43-62.

Blackstad, T. W. (1956) Commissural connections of the hippocampal 
region in the rat, with special reference to their mode of termination. J. Comp. Neurol. 105: 417-537.

Brudzynski, S., and G. J. Mogenson (1985) Association of the mesencephalic locomotor region in locomotor activity induced by injections of amphetamine into the nucleus accumbens. Brain Res. 234: 77-84.

Cajal, S. Ramon y (1911) Histologie du Système Nerveux de l'Homme et des Vertébrés, vol. II, A. Maloine, Paris.

Carlsen, J., J. de Olmos, and L. Heimer (1982) Tracing of two-neuron pathways in the olfactory system by the aid of transneuronal degeneration. Projections to the amygdaloid body and hippocampal formation. J. Comp. Neurol. 208: 196-208.

Gerfen, C. R., and P. E. Sawchenko (1984) An anterograde neuroanatomical tracing method that shows the detailed morphology of neurons, their axons and terminals: Immunohistochemical localization of an axonally transported plant lectin, Phaseolus vulgaris leucoagglutinin. Brain Res. 290: 219-238.

Goldman-Rakic, P. S., L. D. Selemon, and M. L. Schwartz (1984) Dual pathways connecting the dorsolateral prefrontal cortex with the hippocampal formation and parahippocampal cortex in the rhesus monkey. Neuroscience 12: 719-743.

Haberly, L. B., and J. L. Price (1978a) Association and commissural fiber systems of the olfactory cortex of the rat. I. Systems originating in the piriform cortex and adjacent areas. J. Comp. Neurol. 178:711740.

Haberly, L. B., and J. L. Price (1978b) Association and commissural fiber systems of the olfactory cortex of the rat. II. Systems originating in the olfactory peduncle. J. Comp. Neurol. 181: 781-808.

Haglund, L., L. W. Swanson, and C. Köhler (1984) The projection of the supramammillary nucleus to the hippocampal formation: An immunohistochemical and anterograde transport study with the lectin PHA-L in the rat. J. Comp. Neurol. 229: 171-185.

Herkenham, M. (1978) The connections of the nucleus reuniens thalami: Evidence for a direct thalamo-hippocampal pathway in the rat. J. Comp. Neurol. 177: 589-610.

Hjorth-Simonsen, A. (1973) Some intrinsic connections of the hippocampus in the rat: An experimental analysis. J. Comp. Neurol. 147: 145-162.

Hökfelt, T., K. Fuxe, and O. Johansson (1974) Pharmacohistochemical evidence of the existence of dopamine nerve terminals in the limbic cortex. Eur. J. Pharmacol. 25: 108-112.

Hyman, B. T., G. W. Van Hoesen, A. R. Damasio, and C. L. Barnes (1984) Alzheimer's disease: Cell specific pathology isolates the hippocampal formation. Science 225: 1168-1170.

Irle, E., and H. J. Markowitsch (1982) Widespread cortical projection of the hippocampal formation in the cat. Neuroscience 7:2637-2647.

Jones, E. G., and T. P. S. Powell (1970) An anatomical study of converging sensory pathways within the cerebral cortex of the monkey. Brain 93: 793-820.

Katz, L. C., A. Burkhalter, and W. J. Dreyer (1984) Fluorescent latex microspheres as a retrograde neuronal marker for in vivo and in vitro studies of visual cortex. Nature 31: 498-500.

Keizer, K., H. G. J. M. Kuypers, A. M. Huisman, and O. Dann (1983) Diamidino yellow dihydrochloride (DY.2HCl): A new fluorescent retrograde neuronal tracer, which migrates only very slowly out of the ccll. Exp. Brain Rcs. 51: 179-191.

Kelly, P. H., P. W. Seviour, and S. D. Iversen (1975) Amphetamine and apomorphine responses in the rat following 6-OHDA lesions of the nucleus accumbens septi and corpus striatum. Brain Res. 94: 507522.

Köhler, C. (1984) Morphological details of the projection from the presubiculum to the entorhinal area as shown with the novel PHA-L immunohistochemical tracing method in the rat. Neurosci. Lett. 45: 285-290.

Köhler, C. (1985) Intrinsic projections of the retrohippocampal region in the rat brain. I. The subicular complex. J. Comp. Neurol. 236: 504-522.

Köhler, C., M. T. Shipley, B. Srebro, and W. Harkmark (1978) Some retrohippocampal afferents to the entorhinal cortex. Cells of origin as studied by the HRP method in the rat and mouse. Neurosci. Lett. 10: $115-120$.

Köhler, C., L. Haglund, and L. W. Swanson (1984) A diffuse $\alpha$-MSHimmunoreactive projection to the hippocampus and spinal cord from individual ncurons in the lateral hypothalamic area and zona incerta. J. Comp. Neurol. 223: 501-514.

Komisaruk, B. R. (1970) Synchrony between limbic system theta activity and rhythmical behavior in rats. J. Comp. Physiol. Psychol. 70: 482-492.

Kosel, K. C., G. W. Van Hoesen, and J. R. West (1981) Olfactory bulb projections to the parahippocampal area of the rat. J. Comp. Neurol. 198: 467-482.

Kosel, K. C., G. W. Van Hoesen, and D. L. Rosene (1983) A direct projection from the perirhinal cortex (area 35 ) to the subiculum in the rat. Brain Res. 269: 347-351.

Krayniak, P. F., R. C. Mcibach, and A. Siegel (1981) A projection from the entorhinal cortex to the nucleus accumbens in the rat. Brain Res. 209: 427-431.

Krettek, J. E., and J. L. Price (1977) Projections from the amygdaloid complex and adjacent olfactory structures to the entorhinal cortex and to the subiculum in the rat and cat. J. Comp. Neurol. 172: 723752.

Kuypers, H. G. J. M., M. Bentivoglio, C. E. Catsman-Berrevoets, and A. T. Bharos (1980) Double retrograde neuronal labeling through divergent axon collaterals, using two fluorescent tracers with the same excitation wavelength which label different features of the cell. Exp. Brain Res. 40: 383-392.

Lechan, R. M., J. L. Nestler, and S. Jacobson (1981) Immunohistochemical localization of retrogradely and anterogradely transported wheat germ agglutinin (WGA) within the central nervous system of the rat: Application to immunostaining of a second antigen within the same neuron. J. Histochem. Cytochem. 29: 1255-1262.

Mellgren, S. J., and B. Srebro (1973) Changes in acetylcholinesterase and distribution of degenerating fibers in the hippocampal region after septal lesions in the rat. Brain Res. 52: 19-36.

Mishkin, M. (1978) Memory in monkeys severely impaired by combined but not separate removal of amygdala and hippocampus. Nature 273: 297-298.

Mogenson, G. J., L. W. Swanson, and M. Wu (1983) Neural projections from nucleus accumbens to globus pallidus, substantia innominata, and lateral preoptic-lateral hypothalamic area: An anatomical and electrophysiological investigation in the rat. J. Neurosci. 3: 189202.

Mogenson, G. J., L. W. Swanson, and M. Wu (1985) Evidence that projections from the substantia innominata to the zona incerta and mesencephalic locomotor region contribute to locomotor activity. Brain Res. 334: 65-76.

O'Keefe, J., and L. Nadel (1978) The Hippocampus as a Cognitive Map, Oxford U. P., Oxford, UK.

Ottersen, O. P. (1982) Connections of the amygdala of the rat. IV. Corticoamygdaloid and intraamygdaloid connections as studied with axonal transport of horseradish peroxidase. J. Comp. Neurol. 205: $30-48$.

Pijnenburg, A. J. J., and J. M. Van Rossum (1973) Stimulation of locomotor activity following injection of dopamine into the nucleus accumbens. J. Pharm. Pharmacol. 25: 1003-1005.

Raisman, G., W. M. Cowan, and T. P. S. Powell (1965) The extrinsic afferent, commissural and association fibres of the hippocampus. Brain 88: 963-996.

Rockel, A. J., and E. G. Jones (1973) The ncuronal organization of the inferior colliculus of the adult cat. I. The central nucleus. J. Comp. Neurol. 147: 11-60.

Rosene, D. L., and G. W. Van Hoesen (1977) Hippocampal efferents reach widespread areas of cerebral cortex and amygdala in the rhesus monkey. Science 198: 315-317.

Ruda, M., and J. D. Coulter (1982) Axonal and transneuronal transport of wheat germ agglutinin demonstrated by immunocytochemistry. Brain Res. 249: 237-246.

Saper, C. B. (1982) Convergence of autonomic and limbic connections in the insular cortex of the rat. J. Comp. Neurol. 210: 163-173.

Sawchenko, P. E., and L. W. Swanson (1981) A method for tracing biochemically defined pathways in the central nervous system using combined fluorescence retrograde transport and immunohistochemical techniques. Brain Res. 210: 31-51.

Scoville, W. B., and B. Milner (1957) Loss of recent memory after bilateral hippocampal lesion. J. Neurol. Neurosurg. Psychiatry 20: 11-21. 
Seltzer, B., and G. W. Van Hoesen (1979) A direct inferior parietal lobule projection to the presubiculum in the rhesus monkey. Brain Res. 179: 157-161.

Shipley, M. T. (1975) The topographical and laminar organization of the presubiculum's projection to the ipsi- and contralateral entorhinal cortex in the guinea pig. J. Comp. Neurol. 160: 127-145.

Shipley, M. T., and K. E. Sorensen (1975) Some afferent and intrinsic connections in the guinea pig hippocampal region and a new pathway from subiculum feeding back to parahippocampal cortex. Exp. Brain Res. (Suppl.) 1: 188-190.

Simerly, R. B., and L. W. Swanson (1986) The organization of neural inputs to the medial preoptic nucleus of the rat. J. Comp. Neurol. 246: $312-342$.

Sorensen, K. E. (1985) Projections of the entorhinal area to the striatum, nucleus accumbens, and cerebral cortex in the guinea pig. J. Comp. Neurol. 238: 308-322.

Sorensen, K. E., and M. T. Shipley (1979) Projections from the subiculum to the deep layers of the ipsilateral presubicular and entorhinal cortices in the guinea pig. J. Comp. Neurol. 188: 313-334.

Sorensen, K. E., and M. P. Witter (1983) Entorhinal efferents reach the caudato-putamen. Neurosci. Lett. 35: 259-264.

Squire, L. R., and S. Zola-Morgan (1983) The neurology of memory: The case for correspondence between the findings for man and nonhuman primates. In The Physiological Basis of Memory, V. A. Deutsch, ed., pp. 199-267, Academic, New York.

Steward, O. (1976) Topographic organization of the projections from the entorhinal area to the hippocampal formation of the rat. J. Comp. Neurol. 167: 285-314.

Steward, O., and S. A. Scoville (1976) Cells of origin of entorhinal cortical afferents to the hippocampus and fascia dentata of the rat. $J$. Comp. Neurol. 169: 347-370.

Swanson, L. W. (1981) A direct projection from Ammon's horn to prefrontal cortex in the rat. Brain Res. 217: 150-154.

Swanson, L. W. (1982) The projections of the ventral tegmental area and adjacent regions: $A$ combined fluorescent retrograde tracer and immunofluorescence study in the rat. Brain Res. Bull. 9: 321-353.

Swanson, L. W., and W. M. Cowan (1977) An autoradiographic study of the organization of the efferent connections of the hippocampal formation in the rat. J. Comp. Neurol. 172: 49-84.

Swanson, L. W., and W. M. Cowan (1979) The connections of the septal region in the rat. J. Comp. Neurol. 186: 621-656.

Swanson, L. W., P. E. Sawchenko, and W. M. Cowan (1981) Evidence for collateral projections by neurons in Ammon's horn, the dentate gyrus, and the subiculum: A multiple retrograde labeling study in the rat. J. Neurosci. 1: 548-559.
Swanson, I. W., T. J. Teyler, and R. F. Thompson (1982) Hippocampal long-term potentiation: Mechanisms and implications for memory. Neurosci. Res. Program Bull. 20: 613-769.

Swanson, L. W., G. J. Mogenson, C. R. Gerfen, and P. Robinson (1984) Evidence for a projection from the lateral preoptic area and substantia innominata to the "mesencephalic locomotor region" in the rat. Brain Res. 295: 161-178.

Van Hoesen, G. W. (1982) The parahippocampal gyrus. New observations regarding its cortical connections in the monkey. Trends Neurosci. 5: 345-350.

Van Hoesen, G. W., and D. N. Pandya (1975a) Some connections of the entorhinal area (area 28) and perirhinal area (area 35) cortices of the rhesus monkey. I. Temporal lobe afferents. Brain Res. 95: 1-24.

Van Hoesen, G. W., and D. N. Pandya (1975b) Some connections of the entorhinal area (area 28) and perirhinal area (area 35) cortices of the rhesus monkey. III. Efferent connections. Brain Res. 95: 39-59.

Van Hoesen, G. W., D. N. Pandya, and N. Butters (1975) Some connections of the entorhinal area (area 28) and perirhinal area (area 35 ) cortices of the rhesus monkey. II. Frontal afferents. Brain Res. 95: 25-38.

Vogt, B. A., and M. W. Miller (1983) Cortical connections between rat cingulate cortex and visual, motor, and postsubicular cortices. $\mathbf{J}$. Comp. Neurol. 216: 192-210.

Vogt, B. A., and A. Peters (1981) Form and distribution of neurons in rat cingulate cortex: Areas 32, 24 and 29. J. Comp. Neurol. 195: 603-625.

Winson, J., and C. Abzug (1978) Neuronal transmission through hippocampal pathways dependent on behavior. J. Neurophysiol. 41: 716-732.

Wouterlood, F. G., and H. J. Groenewegen (1985) Neuroanatomical tracing by use of Phaseolus vulgaris-leucoagglutinin (PHA-L) electron microscopy of PHA-L filled neuronal somata, dendrites, axons, and axon terminals. Brain Res. 326: 188-191.

Wyss, J. M. (1981) An autoradiographic study of the efferent connections of the antorhinal cortex in the rat. J. Comp. Neurol. 199: 495512.

Wyss, J. M., L. W. Swanson, and W. M. Cowan (1979) A study of subcortical afferents to the hippocampal formation in the rat. Neuroscience 4: 463-476.

Zola-Morgan, S., L. R. Squire, and D. G. Amaral (1986) Human amnesia and the medial temporal region: Enduring memory impairment following a bilateral lesion limited to field CA1 of the hippocampus. J. Neurosci. 6: 2950-2967. 